\title{
Computers and the primary curriculum: an action research case study
}

\author{
Geoff Romeo \\ Monash University \\ Victoria \\ Australia
}

\begin{abstract}
This paper reports on an action research case study. The project involved nine classroom teachers using the action research process to develop an integrated curriculum algorithm and software classification system. The project also aimed to empower individual teachers with the knowledge, skill and confidence to understand, improve and transform their teaching procedures and practices with respect to the use of computers in primary classrooms. The discussion focuses on the development of the algorithm and the selection of a suite of software for the investigation of integrated curriculum topics. Also discussed is the impact of this type of instructional strategy on student and teacher motivation and performance. Also the lessons learnt in regard to software development, professional development, and the effectiveness of action research as a change agent.
\end{abstract}

Main conference themes: learner centred learning

Educational areas: primary education

Study topics:

Secondary keywords: classroom practice, curriculum development, teaching methods, research 


\section{INTRODUCTION}

This paper reports on an action research project conducted by practising classroom teachers at a large suburban primary school in Melbourne, Australia. Mossgiel Park Primary School is located thirty kilometres south east of Melbourne. It is a large school with over five hundred pupils and about 30 staff. One of the most challenging problems facing the school during the 1980s and early 1990s was the development and implementation of a school based curriculum.

In Victoria support for school based curriculum came from the Frameworks project. The project published a number of documents outlining government policy concerning state curriculum and suggested appropriate strategies for the implementation of that policy [1].

Mossgiel Park, and many other schools across the state, struggled, for a variety of reasons, to come to grips with the design and development of school based curriculum within the government framework. Adding to the confusion and frustration was the arrival of the microcomputer. any schools designed successful and innovative programs, but at Mossgiel Park the development of school based curriculum for computers suffered the same fate as other curriculum projects. An unstable teacher base, lack of resources and a lack of expertise in the school based curriculum process combined with a lack of computer literacy and an unfamiliarity with the basic assumptions and rationale underpinning the emerging computers in education movement to further frustrate and confuse.

By 1990 senior staff at the school realized that some action was needed. That action came in two stages. Firstly during the latter half of 1990, year six teachers engaged in their own action research in an effort to investigate and change their practices in regard to the use of computers in the classroom. This resulted in the development of an integrated curriculum algorithm which incorporated a software classification system. The second stage was a systematic and rigorous action research project involving teachers from each grade level and aiming at development of the curriculum algorithm and software classification system in such a way that it could be adapted across grade levels and cater for a variety of teaching styles.

Responsibility for the coordination and documentation of the project was given to a senior classroom teacher, the writer of this paper, who was a parttime candidate for a Doctor of Philosophy degree in Monash University's Education Faculty. The project became the subject of the candidate's dissertation. 


\section{STAGE ONE: THE PILOT PROJECT}

During 1990, year six teachers asked themselves two questions:

- What are the basic assumptions and rationales underpinning the Frameworks philosophy and how do they translate into practice?

- What role has the computer to play in aiding the teacher to realize those practices?

An investigation of the Frameworks documents revealed that for primary classrooms the recommended methodology for the implementation of curriculum was an integrated curriculum approach.

\section{Integrating the curriculum}

An integrated curriculum design focuses mainly on the nature of the child as a learner and the processes involved in the development of thinking and learning. It is designed to promote and enhance children's thinking and learning and is interdisciplinary in that it demonstrates the interdependent nature of the subject disciplines.

One strategy for integrating the curriculum is detailed in Learning Through an Integrated Curriculum: Approaches and Guidelines [2]. The curriculum content is divided into topics and each topic becomes the basis for a classroom investigation or inquiry. Central to the design is the blurring of lines between subject areas. Instead of dividing the classroom activities into subjects the teacher divides them into Central, Related, and Revision and Consolidation Activities. A series of steps or procedures is suggested which teachers can follow in order to implement an integrated curriculum topic [2, p. 42]. This is referred to as a curriculum algorithm [3].

\section{Classifying software for use in the integrated curriculum}

Participants in the pilot project realized that the potential existed for the use of a variety of computer software. What was needed however was a framework which would guide teachers in their choice of software. The following classification was put forward and put to trial during stage one.

\section{Cornerstone software}

Where available a program was selected to be the cornerstone of the topic. Programs such as adventure games could be used by cooperative learning groups on a regular basis to motivate the children, stimulate the cognitive domain and help with the investigation of the topic. 


\section{Supporting software}

Programs supporting investigation of particular aspects of the topic.

\section{Application software}

Software not pertaining to any particular theme or topic such as software for producing documents, worksheets, puzzles, graphics, databases, and so on.

Teachers were encouraged to consider a relevant suite of software consisting of a cornerstone piece, supporting software and applications software [4].

\section{STAGE TWO: ACTION RESEARCH}

\section{The purpose of the project}

A more systematic and rigorous investigation was planned for 1991. Nine classroom teachers (the action group) from Prep to Year six joined a project which would use the action research process to develop and evolve the integrated curriculum algorithm. The action group chose two objectives to drive the inquiry:

- develop and evolve the integrated curriculum algorithm and software classification system as described in the pilot project;

- empower individual teachers with the knowledge, skill and confidence to, understand, improve and transform their teaching procedures and practices in regard to the use of computers in primary classrooms.

It was also decided to investigate the impact of the project on students and teachers, the effectiveness of the project as a professional development strategy, the quality and suitability of the software and hardware used in the project, and to comment on the efficacy of action research.

\section{The research design}

Each member of the action group agreed to do two units of work with their class (two members of the group only managed to complete one unit each). Each unit of work was based on the integrated curriculum algorithm which incorporated the software classification system developed in the pilot project. Each member used the action research cycle (plan, act, observe, reflect) on an individual basis attempting to improve the algorithm, increase knowledge about the software classification system, empower, improve and transform their own teaching, and seek answers to the research questions. 
Each member of the action group was responsible for:

- Working through the action research spirals and recording their observations;

- Attending regular seminars to discuss the project;

- Consulting with each other and with the coordinator on an individual basis;

- Maintaining certain documents for recording events as they happened;

- Answering questionnaires and interview questions both written and recorded;

- Surveying of children to gather their responses to the project;

- Collection of samples of children's work;

- Administration of questionnaires to students;

- Collection and photocopying of relevant primary documents.

\section{Data collection}

Three strategies for data collection were employed:

\section{Observation}

Instruments used to record observations during the course of the investigation included personal journals, field notes/anecdotal records, video and audio recordings.

\section{Primary documents}

A number of primary documents were collected for analysis including documents from the Directorate of School Education (Victoria), Mossgiel Park Primary School administration and individual classroom records.

\section{Questionnaires/interviews}

Students and teachers also completed written questionnaires and video taped interviews.

\section{Data presentation and analysis}

The analysis of the data took place in two stages. Firstly, because of the nature of action research, it was necessary to analyze the data collected immediately so that informed decisions could be made for the next step in the action research cycle. Secondly, a deeper and more reflective analyzis was conducted after the action research cycles were completed to determine whether research objectives were met and to what extent research questions were answered.

In the second stage a coding system was used to conceptualize the data and tease out relevant findings and with the aid of specialized computer software, NUDIST [5], on line and off line documents, such as transcripts from seminars and interviews, questionnaires, field notes and teacher journals were coded. NUDIST simplified the extraction of text, related to a particular 
theme or concept, from a cross section of documents. In this way conjectures, assertions and assumptions were investigated and rejected or substantiated.

\section{Discussion}

This paper focuses on the development of the curriculum algorithm and the software classification system. Figure 1 represents the final version of the algorithm (List 1) which is not so much an end product, but a beginning, a starting point for primary teachers to adapt and change to suit their own students and their own circumstance. It represents a framework for teachers wanting to adopt an inquiry approach that exploits computer technology.

List 1 Integrated curriculum algorithm

1. SELECTING THE TOPIC Identifying an area of investigation.

2. INTRODUCTORY ACTIVITY Sows the seeds of curiosity, helps children to tune in, anchor their thoughts.

3. BRAINSTORM What do the children already know about the topic?

4. CONCEPT AREAS Develop what children already know into concept maps.

5. BRAINSTORM What would the children like to know about the topic? Further develop concept maps.

6. FOCUS AND CONTRIBUTING QUESTIONS Children and teacher use concept maps to develop focus and contributing questions which will drive the inquiry.

Focus questions are broad general questions which focus on the main issues/concepts and will drive the inquiry: How? Why?

Contributing questions further explore particular aspects of the main issues/concepts: Who? What? Where? When?

7. BRAINSTORM Children help to design activities. (Optional)

8. RESOURCE RECONNAISSANCE Collection of resources to aid investigation - books, audio / visual, charts, maps, excursions, guests, etc.

\section{The software suite}

Cornerstone answers to focus and contributing questions, motivation, cognitive and affective domains, whole language, children actively involved, an intellectual challenge. 
Supporting support of the investigation of a particular issue, concept or question. May only be relevant once.

Application does not pertain to any particular topic or issue. The tools can be used by teachers and children.

\section{IMPLEMENTATION A strategy for implementing the investigation}

The curriculum plan-represents a week's work

Central activity: A creative problem solving activity [6]. Helps to answer focus questions. An intellectual challenge. Does not pertain to one particular subject area but draws on the skills and competencies of many. Can use supporting and application software to aid design.

Related activities: A selection of activities pertaining to all subject areas and related to the particular issue, concept or question being investigated. Caters for a wide range of interests and abilities. Uses Bloom's Taxonomy to aid in design and selection [7] [8]. Can use supporting and application software to aid design.

Revision and consolidation activities: Not necessarily related to the exploration of the topic but concentrating on the development, revision and consolidation of specific skills. More subject based, e.g. reading, maths, spelling, writing, word processing. Can use supporting and application software e.g. tutorial, drill and practice, Hypercard stacks.

Individual project: An on going activity designed to teach data collection, application and presentation, time management skills. Linked to focus questions (optional). Uses Bloom's Taxonomy to aid in design and selection of questions $[7,9]$. Designed so some questions require the use of cornerstone, supporting and/or application software.

10. EVALUATION...Systematic collection of quality data.

Fig. 1 List showing the final version of the curriculum algorithm

\section{WHAT IS THE ROLE OF THE CORNERSTONE PROGRAM?}

The cornerstone program is like an on going central activity. The students work on the program in groups of 2 or 3 keeping notes, discussing solutions, gathering data, exploring software 2 to 3 times per week. Research suggests that cornerstone programs can be selected from a range of software genres including, besides adventure games, fixed databases, problem solving programs, simulations and interactive fiction. 
If selected carefully, the program helps to:

- Generate interest and enthusiasm in the topic (motivation);

- Present students with an intellectual challenge (cognitive domain);

- Involve children in a cooperative learning environment (affective domain);

- Establish a whole language environment (reading, writing, speaking, listening);

- Answer focus and contributing questions;

- Heighten curiosity and add new contributing questions.

\section{WHAT ARE THE ADVANTAGES OF ADOPTING THE INTEGRATED CURRICULUM ALGORITHM?}

An inquiry/integrated curriculum allows students to participate in curriculum planning and decision making involving them in activities where they can solve problems, make decisions, analyze, take action, evaluate, invent, experiment, question, imagine, explore social situations, dramatize real events, develop a number of thinking skills and processes, think about learning and the processes used in learning, practise the use of a wide range of different styles of learning, and make decisions about what they want to learn and do [10].

By also incorporating the software classification system not only is student learning further enhanced, but teachers have a framework enabling them to use computers in their classrooms for authentic purposes. This framework is not hardware specific nor does it matter whether you have a computer lab or a single computer in the classroom. Software can be integrated at three levels: cornerstone, supporting or application. Teachers therefore can choose all three or just one depending on available resources. Advances in technology and new software can be accommodated as it becomes available.

\section{Some findings about the use of the curriculum algorithm}

The basic tenet of the algorithm is applicable to all grades preparatory to 6 . However the balance between student input and teacher direction was skewed across grade levels and as students in all grade levels attempted the strategy for the first time. The software component can be removed from the algorithm, but evidence suggests that gains in motivation, commitment and participation may not be as great. This would also mean loss of computer literacy skills and unique learning experiences.

Participants liked the software classification system and especially liked computer use providing the children with activities which were intellectually stimulating and authentic. 


\section{CONCLUSION}

The development of the integrated curriculum algorithm and software classification system were only one part of the project. Findings are based on the systematic observation which took place over the twelve months of the project and on the analyzis of data using coding processes. There is insufficient room to detail all the findings in this paper, however some brief comments can be made.

\section{Student Performance}

In all classrooms there was an increase in motivation, more significant in the upper grades especially grades four, five and six. Evidence also suggests that there was increased commitment to classroom activities and greater participation in cooperative group work. Again this was more noticeable in upper grades.

In general, although not supported by statistical evidence, teachers believed that overall performance of most students improved during the project especially in relation to language development. Specific students with poor language and social skills made exceptional advances.

\section{Teacher performance}

All participants believed that the project increased their skill, knowledge and understanding in regard to the use of computers in the classroom. Analyzis confirmed this view, but the increase in skill, knowledge and understanding differed among individuals. Some participants were revitalized by the whole project displaying increased motivation, participation and commitment to teaching. The use of computer resources increased significantly, as did the discourse about software, hardware and the use of computers in the classroom.

\section{Hardware}

The greatest single deterrent to the use of the computer was the physical transportation of the hardware to the classroom. Machines were attached to trolleys and stored in a centrally secure area each night. The notion of one computer per classroom was seriously challenged by all participants. Exploiting the full range of applications from the software suite required more than one computer. Many felt that 4-6 computers per classroom were needed .

\section{Software}

Participants were concerned about the quality of educational software available. It was felt that there was a need to increase Australian content and develop a range of titles across different genres. 


\section{Professional development}

Strategies of the project were compared to the Principles of Good Adult Learning and Teacher Development Practice [11] which were developed from a review of successful practices and study of the research literature. This project compared favourably as it supported and encouraged participants to relate new knowledge to their career and classroom experiences. It also was innovation focused, provided a conducive setting, focused on practice and the sharpening of skills, displayed collaborative and committed leadership, established relevant internal and external support structures, and encouraged joint planning and collaborative control.

\section{Action research}

Many participants viewed action research more favourably than traditional academic research as it was more related to practice and valued their opinions and insights as professional people. However this type of research relies on careful planning, innovative action, detailed observation, and deep reflection makes it time consuming and demanding. For the classroom teacher it requires a deep commitment to solve the problem. For researchers and facilitators it requires exceptional interpersonal skills to hold the whole project together.

\section{REFERENCES}

1. Ministry of Education, Schools Division, Victoria. (1988) The School Curriculum and Organisation Framework. Ministry of Education, Victoria, Melbourne, Chapter one.

2. Mathews, B.J. (1985) Learning Through an Integrated Curriculum... Curriculum Branch, Ministry of Education (Schools Division), Victoria, Melbourne.

3. Print, M. (1991) Curriculum Development and Design, 2nd edn. Allen and Unwin, Nth Sydney, pp. 61-62.

4. Romeo, G.I. (1991) Computers and the Primary Language Curriculum: An Action Research Project, in 9th Australian Computers in Education Conference Proceedings, ACEC Gold Coast, Queensland, p. 19.

5. Richards. T., Richards, L., McGalliard, J. and Sharrock, B. (1992)

Nudist 2.3 (computer software) Replee Pty Ltd in association with La Traobe University, Melbourne. 
6. Dalton, J. (1985) Adventures in Thinking. Nelson, Melbourne, Section one.

7. Dalton, J. and Smith, D. (1986) Extending Children's Special Abilities. Department of School Education, Victoria, Melbourne, Chapter three.

8. Crawford, J. (ed) (1991) Units of Work for Levels P-8. Directorate of School Education, Victoria, Melbourne, Chapter one.

9. Crawford, J. (ed) (1991) Achieving Excellence... Directorate of School Education, Victoria, Melbourne, Chapter one.

10. Ministry of Education, Schools Division, Victoria. (1988) The School Curriculum and Organisation Framework. Ministry of Education, Victoria, Melbourne, p. 20.

11. Department of Employment, Education and Training (DEET) (1988) Teachers Learning: Improving Australian schools through Inservice Teacher Training and Development. Australian Government Publishing Service, Canberra. p. $23 \mathrm{ff}$. 